\title{
Sand Goby-An Ecologically Relevant Species for Behavioural Ecotoxicology
}

\author{
Davide Asnicar ${ }^{1,2}$, Giedrè Ašmonaite 2 (1), Lina Birgersson ${ }^{2}$, Charlotta Kvarnemo ${ }^{2,3}$ (1), \\ Ola Svensson ${ }^{2,3,4}$ (D) and Joachim Sturve ${ }^{2, *}$ \\ 1 Department of Biology, University of Padova, 35131 Padova, Italy; davide.asnicar@studenti.unipd.it \\ 2 Department of Biological and Environmental Sciences, University of Gothenburg, Box 463, \\ SE-405 30 Göteborg, Sweden; giedre.asmonaite@bioenv.gu.se (G.A.); lina.birgersson@bioenv.gu.se (L.B.); \\ lotta.kvarnemo@bioenv.gu.se (C.K.); ola.svensson@sh.se (O.S.) \\ 3 The Linnaeus Centre for Marine Evolutionary Biology, University of Gothenburg, \\ SE-405 30 Gothenburg, Sweden \\ 4 School of Natural Sciences, Technology and Environmental Studies, Södertörn University, \\ SE-141 89 Huddinge, Sweden \\ * Correspondence: joachim.sturve@bioenv.gu.se; Tel.: +46-317-863-688
}

Received: 30 December 2017; Accepted: 14 February 2018; Published: 20 February 2018

\begin{abstract}
Locomotion-based behavioural endpoints have been suggested as suitable sublethal endpoints for human and environmental hazard assessment, as well as for biomonitoring applications. Larval stages of the sand goby (Pomatoschistus minutus) possess a number of attractive qualities for experimental testing that make it a promising species in behavioural ecotoxicology. Here, we present a study aimed at developing a toolkit for using the sand goby as novel species for ecotoxicological studies and using locomotion as an alternative endpoint in toxicity testing. Exposure to three contaminants (copper $(\mathrm{Cu})$, di-butyl phthalate (DBP) and perfluorooctanoic acid (PFOA) was tested in the early life stages of the sand goby and the locomotion patterns of the larvae were quantified using an automatic tracking system. In a photo-motor test, sand goby larvae displayed substantially higher activity in light than in dark cycles. Furthermore, all tested compounds exerted behavioural alterations, such as hypo- and hyperactivity. Our experimental results show that sand goby larvae produce robust and quantifiable locomotive responses, which could be used within an ecotoxicological context for assessing the behavioural toxicity of environmental pollutants, with particular relevance in the Nordic region. This study thus suggests that sand goby larvae have potential as an environmentally relevant species for behavioural ecotoxicology, and as such offer an alternative to standard model species.
\end{abstract}

Keywords: locomotion; Gobiidae; fish larvae; behaviour; ecotoxicology

\section{Introduction}

Chemical monitoring programs worldwide are documenting increasing levels of pollution in aquatic ecosystems. Coastal environments are continuously subjected to diverse chemical pollution, deriving from offshore oil spills, industrial and agricultural runoff, or domestic waste discharges. It has been estimated that more than 100,000 potentially hazardous substances could be leaking into the environment from anthropogenic activities [1]. With respect to increasing environmental pollution, it is important to investigate the effects of complex chemical mixtures on aquatic organisms and assess their overall impact on the health and functioning of ecosystems. Over the years, various biochemical and physiological approaches have been developed and deployed for assessing pollution-induced consequences on different aquatic organisms, and biomarkers have become an integral part of biomonitoring programs worldwide [2-5]. The prevalence and diversification of anthropogenic 
pollution raises demand for development of new techniques and approaches for pollution assessment and monitoring in the aquatic environment. The increased availability of OMICS (genomics, transcriptomics, proteomics, and metabolomics) techniques has stimulated research and development of novel molecular endpoints for toxicity assessment of various environmental pollutants [6-8]. Such techniques are well suited as early warning signs of exposure, are highly valuable for detecting changes at molecular level and can provide mechanistic toxicological information, but do not implicitly relate to adverse effects on individuals or at the population level [9]. Therefore, the development of novel and robust tools, designed to detect sublethal effects of environmental contaminants at individual and population level is needed.

Recently, behaviour has been proposed as a sensitive and integrative tool for sublethal toxicity screening for various environmental chemicals [10-12]. Several studies have reported that analysis of the swimming activity of larval stages of fish could provide predictions of mechanisms of action of unknown or less known compounds [13-17]. Behavioural studies using automatic video tracking systems have been shown to be successful for toxicity screening of different contaminants, like endocrine disrupting chemicals (EDCs), nanoparticles and metals [18,19], including complex mixtures [20-22]. Increasing recognition and use of behavioural endpoints in ecotoxicological studies is promoting interest for inclusion of behavioural effects as an alternative for lethal endpoints in environmental hazard assessment $[12,23,24]$. The use of locomotive characteristics for toxicological applications in various animal models, such as fish, amphibians [25,26], crustaceans [27,28], insects [29], nematodes [10] or mollusc larvae [30], has been described. This not only highlights the usefulness of video tracking systems for ecotoxicological applications, but also reveals the versatility of locomotion tracking tools and emphasizes the need for translatability and validation of behavioural assays across different biological domains.

The early life stages of animals are known to be particularly susceptible to environmental stress and are affected by both biological factors and physical factors such as water transparency, temperature and salinity [31-34]. Animals at early developmental stages have been found to be more sensitive than other stages to contaminants [35]. Toxicity tests using early life stages of fish are already extensively used for regulatory purposes [36,37] and have proven useful for predicting long-term consequences on organisms [38,39]. Besides the use of fish early life stages for chemical screening of single compounds, this approach could potentially be used for assessing the effects of complex (environmental) mixtures or employed for monitoring water quality [13,40-43].

The sand goby (Pomatoschistus minutus) is a small fish of the Gobiidae family with a widespread distribution along European coasts [44]. The species inhabits soft or sandy bottoms, and can be found across different temperature and salinity ranges from marine to brackish water [45-47]. Its reproductive behaviour has been reviewed by Breder \& Rosen [48] and Forsgren [49]. In short, spawning takes place during spring and early summer (April to July on the Swedish west coast). During this season, male sand gobies build nests by excavating a space underneath a bivalve shell, or similar hard substrate, and covering the top with sand [50]. The male then tries to attract females to the nest by visual and acoustic courtship, and, if accepted, the female will lay her eggs as a single layer on the inside of the nest. The male fertilizes the eggs and exhibits parental care by tending to the eggs, fanning and guarding them until they hatch [51-53]. Females may spawn with several partners over the reproductive period and nests typically contain eggs from more than one female [54-56].

The sand goby is a valuable and ecologically relevant marine fish species for ecotoxicological studies [57-64] and has even been proposed as a potential sentinel species for environmental monitoring [65]. Disruption of adult behaviour after exposure to sewage effluent and xeno-estrogens has been shown, together with gene expression measurements of common ecotoxicological markers such as hepatic vitellogenin [59,62]. Because adult sand gobies display a number of well-documented reproductive behaviours, including courtship, male competition and parental care, this species has been a suitable species for studying endocrine disruptors that affect such behaviours $[57,59,60,62,66]$. In contrast to adult behaviour, the behaviour of sand goby larvae is still poorly understood. Because egg 
development is relatively slow, especially early in the breeding season when water temperatures are low, a parental male will normally stay with his eggs for a considerable time (approximately 2-4 weeks in 8-12 ${ }^{\circ} \mathrm{C}, 1-2$ weeks in $12-18{ }^{\circ} \mathrm{C}$; [67]). This means that both breeding males and developing embryos are likely to be exposed to any pollution in the sediment or water column.

In light of increasing and diverse pollution, there is an urgent need for the development of new approaches for monitoring environmental pollution in the aquatic environment and for the establishment of new protective measures to ensure the health of aquatic ecosystems. The aim of this study was to explore the potential of using early stages of sand goby as novel species for ecotoxicological studies. Here, we specifically examine the possibility of using automatic locomotion tracking methods for behavioural testing of sand goby larvae, which have been proven to be a sensitive tool for toxicity screening for various environmental chemicals in model species. A pilot study focusing on behavioural toxicity assessment of three common environmental pollutants (copper $(\mathrm{Cu})$, di-butyl phthalate (DBP) and perfluorooctanoic acid (PFOA)) on sand goby larvae was performed. Within the scope of this project, we also assessed the feasibility of rearing the species under laboratory conditions and attempted to develop a methodology suited for ecotoxicological testing.

\section{Results}

\subsection{Photo-Motor Response of Sand Goby Larvae}

The locomotion of sand goby larvae was quantified in a behavioural assay using alternating light and darkness as a locomotion-inducing stimulus (Figure 1). Early larval stages of sand goby (at 13-14 days post fertilization, dpf) showed repeatable locomotive patterns: relatively high activity under light and low activity under dark conditions. In each light cycle (5 min), the swimming activity of sand goby larvae consistently increased until the switch to darkness. After the onset of the dark cycle, the activity quickly $(1 \mathrm{~min})$ stabilized to a baseline level $(5-10 \mathrm{~mm} / \mathrm{min})$. Such locomotive responses were consistently recorded in fish larvae, subjected to artificial light stimulation, for both control and exposed larvae (Figure 1). To exemplify the differential locomotive responses of sand goby larvae in a photo-motor test after toxicant exposure, a representation of swimming activity in five light:dark cycles of $\mathrm{Cu}(1 \mu \mathrm{g} / \mathrm{L})$ in exposed and control goby larvae is displayed (Figure 1).

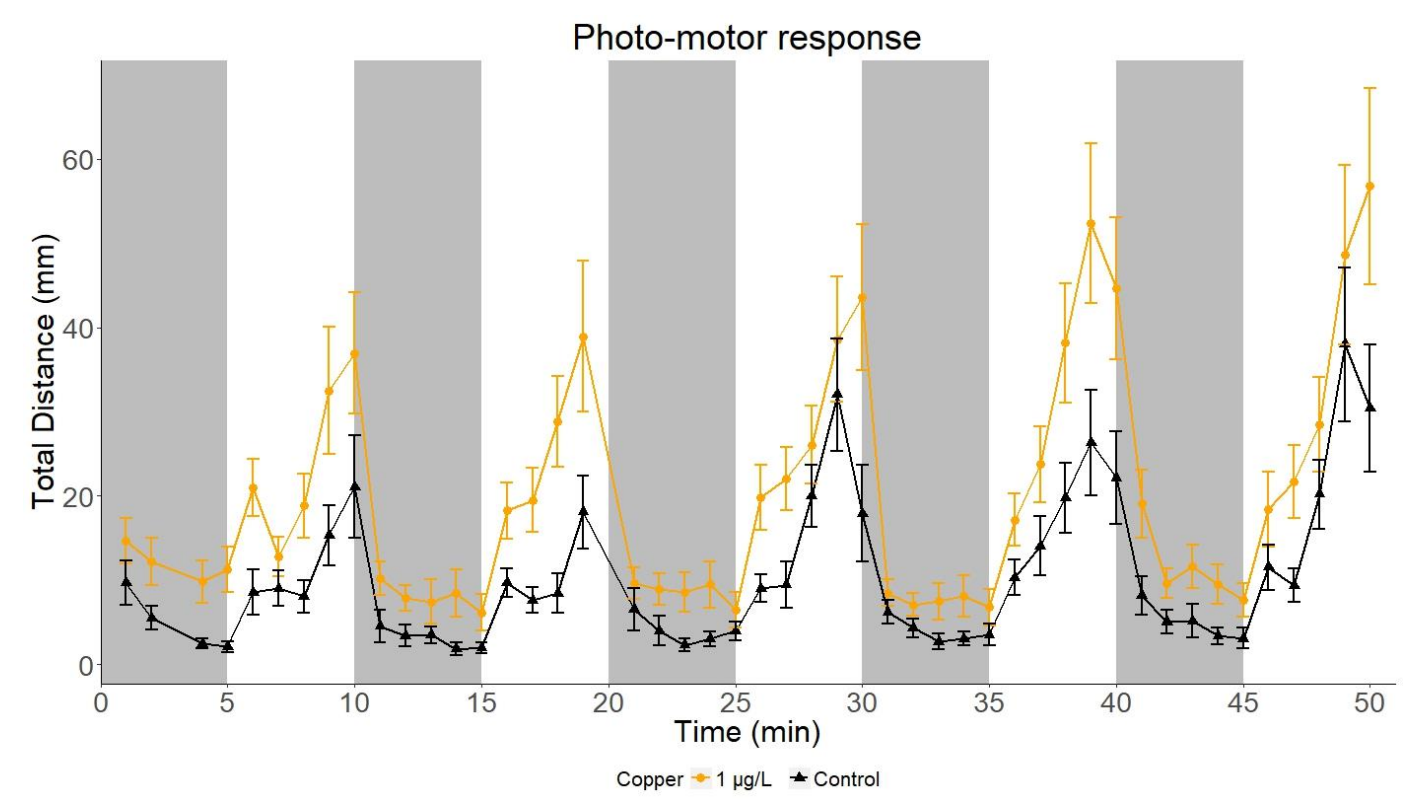

Figure 1. Photo-motor response of sand goby larvae exposed to copper $(1 \mu \mathrm{g} / \mathrm{L}, n=31)$ compared to control larvae $(n=38)$, tested under five cycles of light (white) and dark (shaded) conditions. 


\subsection{Locomotion-Based Behavioural Endpoints}

Behavioural toxicity assessment consisted of analysis of three locomotion-based endpoints: activity (measured as counts of movements), duration and distance travelled that were analysed along the toxicant exposure gradient in light and dark cycles and compared to a control. All tested xenobiotic compounds caused behavioural alterations, including hyper- and hypoactivity (Figures 2-4). Detailed statistical information is provided in the Supplementary Materials (Table S1).

\subsubsection{Number of Movements}

Exposure to $\mathrm{Cu}, \mathrm{DBP}$ and PFOA affected the locomotive activity (number of movements performed) of sand goby larvae in both dark cycles and in light cycles (Figure 2). Statistically significant differences (compared to control) were detected at the $\mathrm{Cu}$ concentrations $0.1,1,10$ and $100 \mu \mathrm{g} / \mathrm{L}$ in dark cycles, and 1, 10 and $100 \mu \mathrm{g} / \mathrm{L}$ in light cycles (Figure 2A). For DBP exposure, a significant effect was found only at the highest concentration in the dark cycles $(1000 \mu \mathrm{g} / \mathrm{L})$, and at all five concentrations tested in the light cycles (Figure 2B). PFOA seemed to affect sand goby larvae activity significantly only in light cycles, in particular at $10 \mu \mathrm{g} / \mathrm{L}$ (Figure 2C). However, the post-hoc analysis did not reveal any significant difference between the control and larvae treated with PFOA in terms of number of movements in the dark cycles.

\subsubsection{Duration of Movements}

Exposure to $\mathrm{Cu}$ significantly affected the duration of larval movements (measured in seconds), in both dark cycles and light cycles (Figure 3A). Statistical significances compared to control were detected at the $\mathrm{Cu}$ concentrations 1 and $10 \mu \mathrm{g} / \mathrm{L}$ in dark cycles and in light cycles. Exposure to DBP significantly increased duration of movement at 1 and $10 \mu \mathrm{g} / \mathrm{L}$ in dark cycles, and from 0.1 to $100 \mu \mathrm{g} / \mathrm{L}$ in light cycles (Figure 3B). For the highest concentration of DBP $(1000 \mu \mathrm{g} / \mathrm{L})$ in light cycles, the duration of movement was significantly lower than in the control. PFOA significantly increased the duration of movement in the light cycles at 1 and $10 \mu \mathrm{g} / \mathrm{L}$ (Figure 3C). The post-hoc analysis did not reveal any significant difference between the control and larvae treated with PFOA in terms of duration of movements in dark cycles.

\subsubsection{Total Distance Travelled}

Results indicated that the distance parameter was also altered by toxicant exposure for all tested compounds (Figure 4). For example, $\mathrm{Cu}$ exposure significantly affected the total distance the larvae travelled, both in dark and light cycles (Figure 4A). Specifically, goby larvae exposed to $1 \mu \mathrm{g} / \mathrm{L} \mathrm{Cu}$ travelled longer distances than control individuals in both light and dark cycles, whereas larvae exposed to $10 \mu \mathrm{g} / \mathrm{L}$ showed increased locomotion only in dark cycles. Moreover, after low DBP exposure (0.1-1 $\mu \mathrm{g} / \mathrm{L})$ larvae seemed to be more active and swam further in light than unexposed animals, whereas after exposure to the highest test concentration $(1000 \mu \mathrm{g} / \mathrm{L})$ the locomotive distance was significantly lower (Figure 4B). This locomotion suppression persisted in both light and dark cycles. Regarding PFOA exposure, statistically significant behavioural effects were detected only in the dark cycles for exposure to concentrations of 1 and $10 \mu \mathrm{g} / \mathrm{L}$ (Figure 4C). There was also a tendency for an increased activity in light at $10 \mu \mathrm{g} / \mathrm{L}$. 

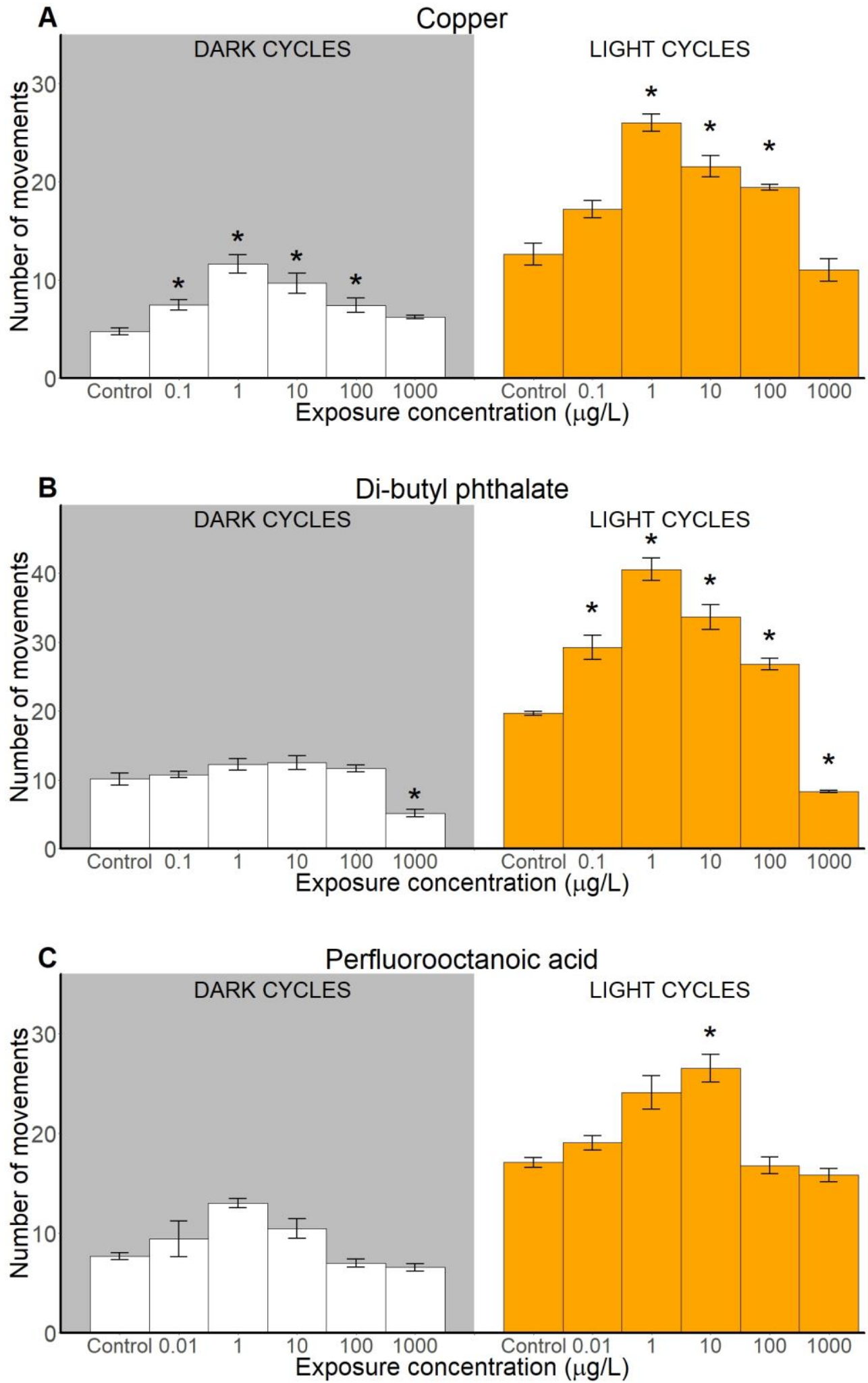

Figure 2. Locomotive activity (measured as number of movements) of sand goby larvae exposed to copper (A), di-butyl phthalate (B), and perfluorooctanoic acid (C). Results presented as means \pm SEM (standard error of the mean) for dark (left) and light (right) cycles. Statistically significant differences $(p<0.05)$ between control and other treatments are indicated with asterisks $\left({ }^{*}\right),(n \geq 31)$. 

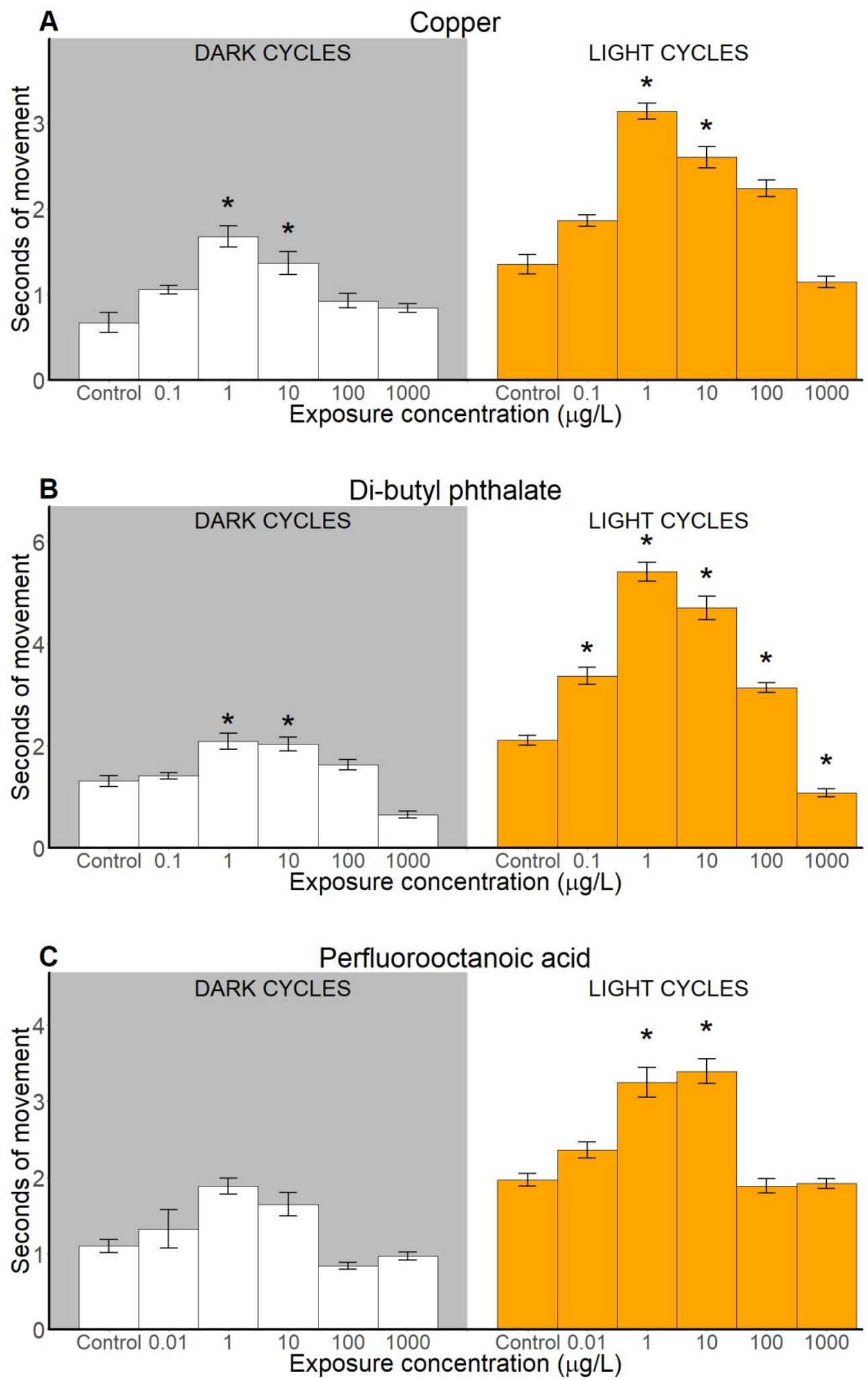

Figure 3. Duration of locomotive activity (measured as seconds) of sand goby larvae exposed to copper (A), di-butyl phthalate (B), and perfluorooctanoic acid (C). Results presented as means \pm SEM for dark (left) and light (right) cycles. Statistically significant differences $(p<0.05)$ between control and other treatments are indicated with asterisks $\left(^{*}\right),(n \geq 31)$. 

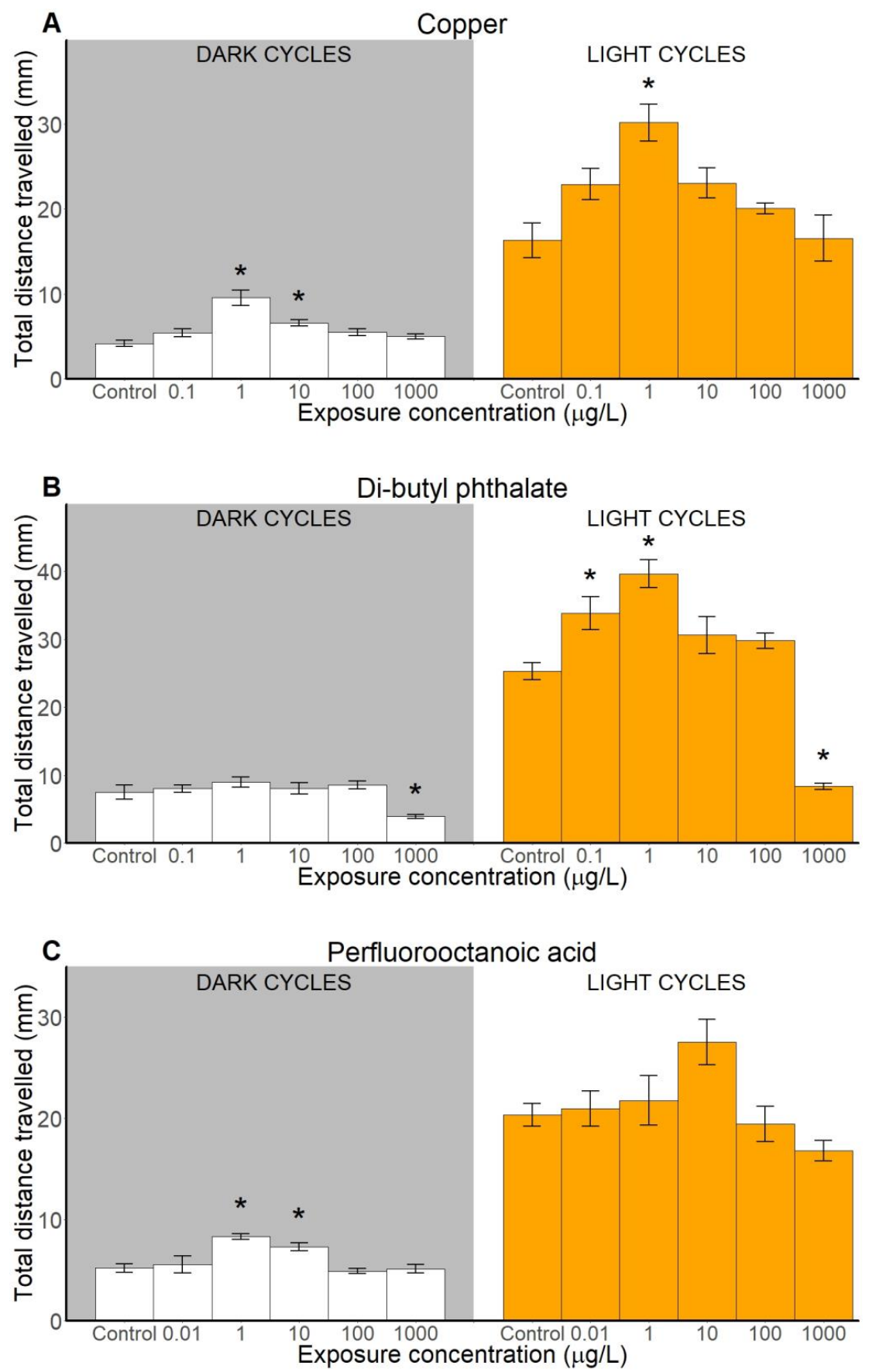

Figure 4. Locomotive distance (measured as distance travelled) of sand goby larvae exposed to copper (A), di-butyl phthalate (B), and perfluorooctanoic acid (C). Results presented as means \pm SEM for dark (left) and light (right) cycles. Statistically significant differences $(p<0.05)$ between control and other treatments are indicated with asterisks $\left({ }^{*}\right),(n \geq 31)$.

\section{Discussion}

Behavioural ecotoxicology is a growing discipline aimed at finding novel and sensitive behavioural endpoints that could be used for sublethal toxicity screening of environmental pollutants $[11,68]$. In the present study, we used sand goby larvae as an ecologically relevant species for the Nordic region and explored whether its locomotive behaviour could be used for screening environmental contaminants. This study is the first to describe the locomotive responses of sand goby 
larvae within a photo-motor test, thereby making use of a behavioural assay that is commonly used for pharmaceutical testing and chemical screening $[15,16,69,70]$. We demonstrated that sand goby larvae at 13-14 dpf are able to respond to light stimulation (19,000 lux) and display robust behavioural patterns. At this early stage of development, the goby larvae were able to detect an external signal and produce a consecutive response to the stimulation. The behavioural assay employed in the present study was directly adapted from zebrafish studies, which have previously been shown to be able to detect sublethal contaminant-induced behavioural changes [18,19].

For all three tested compounds, we were able to establish dose-response relationships between each single locomotion variable and the toxicant exposure gradient. The observed behavioural changes were in line with previously published sublethal toxicity margins [71-74]. The observed toxicant-induced locomotive disturbances support the use of locomotion-based endpoints for sublethal toxicity screening. Two of the tested compounds (DBP and PFOA) are well-known EDCs [75-78], which may exert biological effects at low exposure levels and generate non-monotonic responses [79]. Interestingly, DBP demonstrated non-monotonic behavioural responses across the concentration gradient for all tested locomotion variables (Figures 2B, 3B and 4B) with significant elevation of locomotion parameters at low concentrations and decrease at the highest concentration. The locomotion assay used in this study may be useful for toxicity screening of endocrine disruptors, which is in agreement with previous studies that have suggested that behavioural endpoints are suitable for EDC screening [80]. Furthermore, a clear increase in swimming activity (in light cycles) was observed in sand goby larvae exposed to environmental levels of $\mathrm{Cu}(1 \mu \mathrm{g} / \mathrm{L})$. A similar elevation in locomotive responses was previously documented using the same photo-motor test in zebrafish exposed to $\mathrm{Cu}$ ions [19]. On the basis of this comparison, we suggest that exposure to $\mathrm{Cu}$ induced similar behavioural disturbances in two different fish species, which exemplifies the versatility of locomotion profiling approach and supports its applicability beyond the standard laboratory species. Moreover, this finding suggests that, despite the intrinsic differences in the behavioural repertoire of fish larvae from these species, changes in locomotion (intensity and/or patterns) could potentially be used as a pragmatic tool for toxicity screening.

It is generally assumed that animals subjected to toxicant exposure experience stress and can enter new and potentially irreversible physiological states. According to the allostatic step-wise stress theory [81,82], organisms exposed to low levels of a stressor (not necessarily toxicant-induced) are capable of mediating the disturbances via homeostasis, while they may be irreversibly harmed when the stressor persists or exceeds the organisms' capacity to cope. Interestingly, we observed dual behavioural modalities, indicating the presence of low-level stimulatory effects of toxicants in low exposure concentrations, and suppressing (toxic) effects in high exposure levels (Figures 2B, 3B and 4B). We could speculate that fish larvae exposed to low levels of toxicants (Figures 2-4) may have experienced metabolic stress (e.g., due to increased physiological needs for detoxification), which thereafter translated to hyperactivity and/or changes in susceptibility to light stimulation. For example, $\mathrm{Cu}$ and DBP exposure have been linked with oxidative stress [83,84], either from a direct toxicant effect or as a result of increased metabolism, which potentially causes observed behavioural disturbances. On the other hand, even though the underlying mechanism(s) of stimulatory (behavioural) swimming response remain largely unknown, a growing body of studies have documented toxicant-induced hyperactivity in fish larvae $[18,85,86]$. Hypothetically, hyperactivity may reflect an adaptive larval response originally evolved to allow avoidance of non-preferred micro-environments. However, in the context of macro-environmental pollutants, such a response is arguably not likely to be beneficial, and may even be harmful to the larvae. Furthermore, the use of high levels of solvents (e.g., dimethyl sulfoxide (DMSO) $0.01-0.1 \%$ ) has been shown to increase locomotion in several aquatic model species [87], which should also be taken into consideration while designing experiments and interpreting the results from behavioural experiments with toxicants dissolved in a carrier medium. Then again, hypoactivity (reduced swimming capacity) may occur due to functional damage exerted on the motoric system, or overall homeostatic arrest, and in such context could be viewed as a behavioural 
disability. That said, explanation of observed behavioural disturbances, e.g., using stepwise-stress theory, validation of behavioural changes across contaminant exposure (concentration) gradients, as well as explanation underlying mechanisms remain prospects for the future. In the broader context of the newly emerging discipline of behavioural ecotoxicology, the interpretation of the adversity of "behavioural effects", as well as extrapolation of such effects on population level, are still subjects for discussion.

Even though our study was limited to three contaminants that are prevalent in coastal environments, we believe that this behavioural screening approach can extend beyond that. For instance, a proposed behavioural toxicity testing strategy could be used for testing complex environmental mixtures (e.g., solid phase extracts) for biomonitoring purposes. Furthermore, the sand goby behavioural assessment using larval stages used here could be further upgraded and potentially coupled with developmental toxicity assessment using traditional apical endpoints (mortality, incidence of malformations, as described in the Fish Embryo Toxicity Test [37]) or with various molecular techniques suited for obtaining comprehensive mechanistic insights of toxicity. Collection of additional toxicological endpoints could undoubtedly support results of behavioural assessment and could aid for data interpretation.

As pointed out above, the locomotion of sand goby larvae has been shown to be suitable for sublethal toxicity screening of xenobiotics. Besides its robust photo-motor response, there are other attractive features of the sand goby species suggesting its applicability in ecotoxicological sciences. For example, a natural nest often contains 5000-10,000 eggs (2000-3000 eggs per female $[44,88]$ ), spawned by 2-6 females per nest [55], which ensures easy collection of fish embryos or larvae sufficient for execution of experiments. They also readily spawn in the laboratory. Notably, with experimental designs that include single female-male breeding (Figure 5A), both intrapopulation variability (within clutches) and interpopulation (between clutches) variability can be systematically controlled, which is highly important for making laboratory-based behavioural studies more ecologically relevant. Also, it is well known that offspring from fish sampled from populations in the field are expected to have higher level of genetic diversity (low inbreeding potential) compared to lab-reared populations. Sand goby larvae (10-14 dpf) that were used in the experiments did not initiate independent feeding, and therefore technically could be considered an in vitro system (according to European legislation), which represents another strength of using the species for toxicological exposures. Furthermore, the applicability of the species for ecotoxicological studies stretches beyond its early life stages. Previously, it has been shown that other life stages of the species possess certain attributes that make them ecologically relevant in ecotoxicology. For example, the short generation time (1-2 years [89]) represents another advantage for the potential application of this species in transgenerational ecotoxicological studies. Moreover, due to interesting reproductive behaviours, the sand goby has been proven to be useful in studies assessing the impacts of compounds with an endocrine mode of action (e.g., $17 \alpha$-ethinyl estradiol in [57,58]).

However, the use of sand goby larvae as an alternative for behavioural ecotoxicology still presents some challenges and there are several methodological considerations for using sand goby as an ecologically relevant species for ecotoxicological experiments. In terms of practical prerequisites for species husbandry and breeding, there are some apparent limitations associated with seasonality. The sand goby normally has a breeding season that covers spring and early summer [49], and therefore exposure of larvae is limited to this season. Even though there is the potential for keeping sand goby and other species in the so-called sand goby group [90] in the laboratory and performing routine breeding in an artificial setup, it unfortunately remains a great uncertainty. Although they are unproblematic to keep in the laboratory all year around and they mature eggs and sperm in spring [91], raising the pelagic larvae until settling has proven to be challenging [92]. Furthermore, depending on water temperature, it takes 1-4 weeks for sand goby larvae to hatch [67], and this period is considerably longer and more variable than for other standard laboratory species such as zebrafish (72 h post fertilization, hpf) and fathead minnow (5 dpf) [93]. For the Japanese medaka, 
another fish species commonly used in ecotoxicological studies, it takes nine days until hatching is completed [94]. The breeding and rearing conditions for the sand goby in the laboratory would need to be carefully controlled to ensure that embryos hatch at the same time and that larvae are at the same developmental stage at the onset of exposure. In addition, high baseline mortality was observed during our experiments, and is a challenge for the use of the sand goby as a model of chemical exposure. The mortality we observed varied between different clutches. Potential explanations for the intrinsically high mortality rates could be insufficient oxygenation, high embryo density on the plastic film, and handling stress (e.g., sensitivity due to transferring larvae). As the male would normally care for the eggs until they hatch, removal of unfit eggs from the nest before hatching may also have an effect on the mortality and quality of artificially reared clutches. Previous studies have also described high mortality rates for the rearing of sand goby larvae [92].

The behavioural toxicity assessment was conducted using an assay designed for zebrafish, and tracking parameters employed in the behavioural protocol may need further refinement to be suitable for sand goby larvae. Optimization of movement differentiation thresholds, as well as the selection of relevant lighting conditions (cycle length, acclimation duration, etc.), may be advised in future studies. For example, the level of light intensity may play an important role in (observed) behavioural responses. In the natural environment, the light intensity in the water column can vary greatly depending on different biotic and abiotic factors. Adult sand gobies used in this study were caught in shallow $(0.5-1 \mathrm{~m})$ coastal areas, with expected lower light intensity than in the experimental setup. It has been previously shown that adult $P$. minutus display nocturnal activity under low light conditions (high activity in darkness and low activity in light) [95]. However, this behaviour may well be ontogenetically flexible or undergo changes during seasons, affected by changes in light intensity. Overall, relatively little is known about the impact of light on sand goby activity patterns, especially how it changes from the early life stages to adulthood. Taken together, even though a solid knowledge base about the biology and behaviours of adults exists, information about the development and ontology of behavioural repertoire of the larvae is still largely lacking (see [92]).

\section{Materials and Methods}

\subsection{Sand Goby Husbandry}

Adult sand gobies (P. minutus) were caught during May 2016 by hand trawling in a clean bay near the Sven Lovén Center for Marine Infrastructure Kristineberg, University of Gothenburg, on the west coast of Sweden ( $\left.58^{\circ} 14^{\prime} 53.8^{\prime \prime} \mathrm{N} 11^{\circ} 26^{\prime} 50.1^{\prime \prime} \mathrm{E}\right)$. Specimens were initially stored at the Kristineberg facility and fed ad libitum with live mysid shrimps (Praunus flexuosus) and mussel meat (Mytilus sp.). After three days the fish were moved to another aquarium facility, located in Gothenburg (Department of Biological and Environmental Sciences, University of Gothenburg), and kept in artificial seawater at $28.4 \pm 1$ practical salinity units (PSU) under $12: 12 \mathrm{~h}$ light:dark cycle at $14^{\circ} \mathrm{C}$. Salinity was measured twice per week. Fish were fed ad libitum three times per week with frozen Chironomidae mosquito larvae (Imazo AB, Vara, Sweden). All fish were treated in accordance with the ethical practices defined by the Swedish Board of Agriculture (Permit number 39-2014).

\subsection{Breeding for Exposures}

Prior to breeding, male and female fish were separated and kept in two separate tanks (200 L) filled with artificial seawater and a sand layer on the bottom. For breeding trials, a closed flow-through system equipped with mechanical, biological and ultra violet (UV) filters with smaller tanks containing $14 \mathrm{~L}$ water, an air stone and a $3 \mathrm{~cm}$ clean sand layer as substrate at the bottom was used. One male and one female were placed in each smaller flow through tank, together with a halved clay pot $(7 \mathrm{~cm} \varnothing)$ that the male could use as a nest site. The inside of the clay pot was covered with a plastic film, which served as a substrate for the eggs. Once the females had laid eggs, they were removed from the tank in order to avoid possible egg predation. Larval development was monitored by visual inspection. 
Shortly before hatching, when the eyes of embryos were visible (after approximately 10-11 days), the plastic film with eggs was transferred from the clay pot to beakers with saline water and allowed to hatch.

\subsection{Chemicals and Exposure Design}

Three compounds, $\mathrm{Cu}, \mathrm{DBP}$ and PFOA, were selected based on a list of commonly found chemicals from a sampling campaign in Swedish west coast waters [96] and were tested as single compounds. Chemicals were purchased from Sigma Aldrich (Stockholm, Sweden). Exposure solutions were prepared in artificial seawater (28.4 PSU) to five nominal concentrations in the range of $0.01-1000 \mu \mathrm{g} / \mathrm{L}$ (PFOA) or 0.1-1000 $\mu \mathrm{g} / \mathrm{L}$ (Cu and DBP). The lowest concentrations for DBP and PFOA were chosen based on the mean environmental concentrations found by Gustavsson et al. [96] and the concentration for $\mathrm{Cu}$ was $1 \mu \mathrm{g} / \mathrm{L}$. For PFOA, a stock solution in DMSO (100\%) was first prepared, and then diluted to final concentrations in artificial seawater containing a maximum of $0.1 \% \mathrm{DMSO}$, in compliance with OECD recommendations [97]. In the control treatment, artificial seawater was used.

The larval exposure was static; for each treatment, a total of nine technical replicates from three clutches (i.e., three per clutch) belonging to three different breeding pairs were used (Figure 5A). Approximately $24 \mathrm{~h}$ after hatching, 30 healthy larvae from each clutch were randomly selected and transferred to glass e-flasks with $90 \mathrm{~mL}$ exposure solution (for each compound and each concentration). Larvae were incubated at $14^{\circ} \mathrm{C}$ with a 12:12 h light:dark cycle. After $48 \mathrm{~h}$ of exposure $(72 \mathrm{~h}$ post hatching), eight larvae per exposure condition were transferred to individual wells of 48-well plates containing $700 \mu \mathrm{L}$ exposure solution. Mortality was not recorded during the exposure, but was estimated to be $20-40 \%$ prior to exposure. Natural, high baseline mortality for sand goby larvae has previously been described [92].

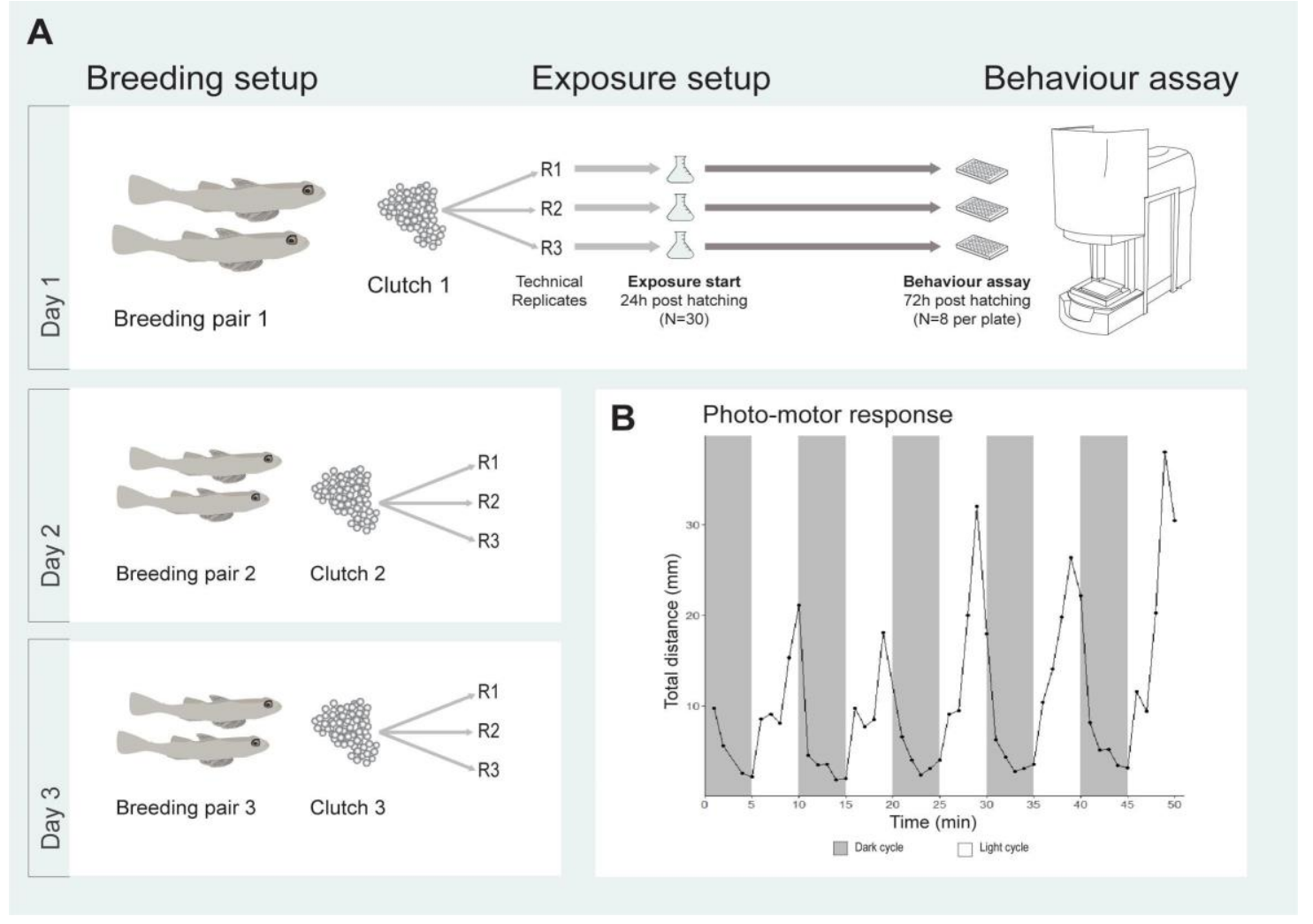

Figure 5. Breeding setup and experimental design for sand goby larvae exposures (A) and behavioural toxicity assay utilizing alternating light and dark cycles (B). The locomotive response of unexposed sand goby larvae is presented. 


\subsection{Behavioural Toxicity Assay}

Prior to assessing the behavioural toxicity of selected compounds, a pilot study was conducted to investigate and describe baseline activity patterns of sand goby larvae in a photo-motor test (Figure 5B). The swimming activity of unexposed goby larvae was quantified using a behavioural assay previously developed for zebrafish larvae [18]. The behavioural protocol was adapted for sand goby larvae with some minor adjustments. The locomotion of the sand goby larvae was quantified using the locomotion tracking with rotation angles module in the automatic behaviour tracking system ViewPoint (ViewPoint Life Science Inc., Montreal, QC, Canada). In order to artificially stress the animal and see its behavioural response in stress conditions, a protocol composed of 10 alternating light:dark cycles (5 min : $5 \mathrm{~min}$ ) was used. Light saturation in light cycles was 100\%, corresponding to 19,000 lux. The larvae were acclimated in light for 15 minutes before initiation of the locomotion assay. Three locomotion-based endpoints were assessed: (1) number of movements; (2) duration of movements; and (3) total distance travelled. In this study we focused on the cumulative movement responses of fish larvae (during behavioural trials), without disseminating information on structural and dynamic components of locomotion. The positions of larvae within the 48 well-plate were randomly assigned to avoid potential plate effects. Also, for each behavioural plate, fish larvae exposed to all test concentrations for each single chemical exposure were included. Moreover, prepared plates were kept for at least 10-40 min before behavioural tracking to eliminate the potential impact of stress induced by handling. The temperature during behavioural experiments was kept constant $\left(16 \pm 1^{\circ} \mathrm{C}\right)$. Behavioural experiments were consistently conducted between 08:30 and 18:30.

\subsection{Data Analysis}

For the statistical analysis, results for dark and light cycles from different technical and biological replicates were averaged. Results are presented as mean values for the three different locomotion endpoints \pm standard error of the mean (SEM). Asterisks represent the statistical significance (i.e., $p$-value $\leq 0.05$ ) between the condition of exposure and the relative control within dark or light cycles. From all the datasets, the values of the 3rd and the 20th min were deleted due to technical problems, probably caused by tracking software issues. These problems were found in all the datasets, without exception; therefore, it was decided to remove those data that could interfere with the further analysis. Moreover, all the data from larvae where movement was not recorded were removed.

Data were checked for normal distribution with the Shapiro-Wilk test and for homoscedasticity with Levene's test. If these two assumptions of analysis of variance (ANOVA) were matched in the data, a one-way ANOVA was used, followed by pairwise $t$-test comparisons of each concentration against the control. This was done as a planned comparison post hoc testing to assess the effect of the tested compound on larval locomotion. Light and dark cycles were analysed separately. If the homoscedasticity assumption was not matched, a Welch's ANOVA test with the Games-Howell post-hoc test was used. If the normality assumption was not matched, a Kruskal-Wallis test followed by a Nemenyi post-hoc test was used. Statistical analysis was performed with the software $\mathrm{R}$ and RStudio [98].

\section{Conclusions}

The current study demonstrates that sand goby larvae can be used to screen for the behavioural toxicity of chemicals present in the marine environment and that the sand goby larval locomotion assay is a promising tool for single chemical hazard assessment on a species relevant for Nordic marine ecosystems. We adapted a behavioural assay developed for zebrafish with the sand goby as a more environmentally relevant species and were able to establish dose-response relationships for measured behavioural endpoints after exposure to single compounds. The early developmental stages of sand goby could also be used for more complex mixtures, as well as in future monitoring studies of complex mixtures, extracts, and water or sediment samples. Furthermore, it could be adapted for 
other species of fish. We conclude that locomotion of fish larval stages can be used as an indicator of sublethal effects of toxicants, and that sand goby larvae have potential for ecotoxicological behavioural studies. However, there are several unresolved challenges, including optimization of behaviour tracking, standardization, breeding limitations and embryo mortality, which should be addressed in future studies.

Supplementary Materials: The following are available online at www.mdpi.com/2410-3888/3/1/13/s1, Table S1: Statistical analysis on sand goby larvae exposed to the three different compounds in dark and light cycles.

Acknowledgments: This project was financed by the FORMAS-funded project "Novel instruments for effect-based assessment of chemical pollution in coastal ecosystems" (NICE).

Author Contributions: D.A. performed the breeding, exposure and locomotion assays and analysed the data; G.A. designed the exposure setup and developed a framework for behavioural data analysis. G.A., L.B. and D.A. wrote the paper; L.B. and D.A. designed and edited the figures; C.K. and O.S. provided their expertise in sand goby husbandry and breeding, and contributed to discussions and critical reading of the manuscript; J.S. designed and supervised the study and contributed to discussions and critical reading of the manuscript.

Conflicts of Interest: The authors declare no conflict of interest.

\section{References}

1. Brockmeier, E.K.; Hodges, G.; Hutchinson, T.H.; Butler, E.; Hecker, M.; Tollefsen, K.E.; Garcia-Reyero, N.; Kille, P.; Becker, D.; Chipman, K.; et al. The role of omics in the application of adverse outcome pathways for chemical risk assessment. Toxicol. Sci. 2017, 158, 252-262. [CrossRef] [PubMed]

2. Beliaeff, B.; Burgeot, T. Integrated biomarker response: A useful tool for ecological risk assessment. Environ. Toxicol. Chem. 2002, 21, 1316-1322. [CrossRef] [PubMed]

3. Livingston, D.R.; Förlin, L.; George, S.G. Molecular biomarkers and toxic consequences of impact by organic pollution in aquatic organisms. In Water Quality \& Stress Indicators in Marine and Freshwater Systems: Linking Levels of Organisation; Sutcliffe, D.W., Ed.; FBA Special Publications; Freshwater Biological Association: Ambleside, UK, 1994; pp. 154-171. ISBN 9780900386534.

4. Wernersson, A.-S.; Carere, M.; Maggi, C.; Tusil, P.; Soldan, P.; James, A.; Sanchez, W.; Dulio, V.; Broeg, K.; Reifferscheid, G.; et al. The European technical report on aquatic effect-based monitoring tools under the water framework directive. Environ. Sci. Eur. 2015, 27, 7. [CrossRef]

5. Sandstrom, O.; Larsson, A.; Andersson, J. Three decades of Swedish experience demonstrates the need for integrated long-term monitoring of fish in marine coastal areas. Water Qual. Res. J. Can. 2005, 40, 233-250.

6. Benninghoff, A.D. Toxicoproteomics-The next step in the evolution of environmental biomarkers? Toxicol. Sci. 2007, 95, 1-4. [CrossRef] [PubMed]

7. Brausch, J.M.; Connors, K.A.; Brooks, B.W.; Rand, G.M. Human pharmaceuticals in the aquatic environment: A review of recent toxicological studies and considerations for toxicity testing. Rev. Environ. Contam. Toxicol. 2012, 218, 1-99. [CrossRef] [PubMed]

8. Miracle, A.L.; Ankley, G.T. Ecotoxicogenomics: Linkages between exposure and effects in assessing risks of aquatic contaminants to fish. Reprod. Toxicol. 2005, 19, 321-326. [CrossRef] [PubMed]

9. Bahamonde, P.A.; Feswick, A.; Isaacs, M.A.; Munkittrick, K.R.; Martyniuk, C.J. Defining the role of omics in assessing ecosystem health: Perspectives from the Canadian environmental monitoring program. Environ. Toxicol. Chem. 2016, 35, 20-35. [CrossRef] [PubMed]

10. Gerhardt, A.; Schmidt, S.; Höss, S. Measurement of movement patterns of Caenorhabditis elegans (Nematoda) with the Multispecies Freshwater Biomonitor ${ }^{\circledR}$ (MFB) - A potential new method to study a behavioral toxicity parameter of nematodes in sediments. Environ. Pollut. 2002, 120, 513-516. [CrossRef]

11. Hellou, J. Behavioural ecotoxicology, an "early warning" signal to assess environmental quality. Environ. Sci. Pollut. Res. 2011, 18, 1-11. [CrossRef] [PubMed]

12. Robinson, P.D. Behavioural toxicity of organic chemical contaminants in fish: Application to ecological risk assessments (ERAs). Can. J. Fish. Aquat. Sci. 2009, 66, 1179-1188. [CrossRef]

13. Ali, S.; Champagne, D.L.; Richardson, M.K. Behavioral profiling of zebrafish embryos exposed to a panel of 60 water-soluble compounds. Behav. Brain Res. 2012, 228, 272-283. [CrossRef] [PubMed] 
14. Jin, Y.; Liu, Z.; Liu, F.; Ye, Y.; Peng, T.; Fu, Z. Embryonic exposure to cadmium (II) and chromium (VI) induce behavioral alterations, oxidative stress and immunotoxicity in zebrafish (Danio rerio). Neurotoxicol. Teratol. 2015, 48, 9-17. [CrossRef] [PubMed]

15. Kokel, D.; Peterson, R.T. Using the zebrafish photomotor response for psychotropic drug screening. Methods Cell Biol. 2011, 105, 517-524. [CrossRef] [PubMed]

16. Kokel, D.; Bryan, J.; Laggner, C.; White, R.; Cheung, C.Y.J.; Mateus, R.; Healey, D.; Kim, S.; Werdich, A.A.; Haggarty, S.J.; et al. Rapid behavior-based identification of neuroactive small molecules in the zebrafish. Nat. Chem. Biol. 2010, 6, 231-237. [CrossRef] [PubMed]

17. Rihel, J.; Prober, D.A.; Arvanites, A.; Lam, K.; Zimmerman, S.; Jang, S.; Haggarty, S.J.; Kokel, D.; Rubin, L.L.; Peterson, R.T.; et al. Zebrafish behavioral profiling links drugs to biological targets and rest/wake regulation. Science 2010, 327, 348-351. [CrossRef] [PubMed]

18. Ašmonaite, G.; Boyer, S.; de Souza, K.B.; Wassmur, B.; Sturve, J. Behavioural toxicity assessment of silver ions and nanoparticles on zebrafish using a locomotion profiling approach. Aquat. Toxicol. 2016, 173, 143-153. [CrossRef] [PubMed]

19. Thit, A.; Skjolding, L.M.; Selck, H.; Sturve, J. Effects of copper oxide nanoparticles and copper ions to zebrafish (Danio rerio) cells, embryos and fry. Toxicol. In Vitro 2017, 45, 89-100. [CrossRef] [PubMed]

20. Khezri, A.; Fraser, T.; Nourizadeh-Lillabadi, R. A mixture of persistent organic pollutants and perfluorooctanesulfonic acid induces similar behavioural responses, but different gene expression profiles in zebrafish larvae. Int. J. Mol. Sci. 2017, 18, 291. [CrossRef] [PubMed]

21. Michiels, E.D.G.; Vergauwen, L.; Hagenaars, A.; Fransen, E.; Dongen, S.V.; Van Cruchten, S.J.; Bervoets, L.; Knapen, D. Evaluating complex mixtures in the zebrafish embryo by reconstituting field water samples: A metal pollution case study. Int. J. Mol. Sci. 2017, 18. [CrossRef] [PubMed]

22. Wang, Y.; Shen, C.; Wang, C.; Zhou, Y.; Gao, D.; Zuo, Z. Maternal and embryonic exposure to the water soluble fraction of crude oil or lead induces behavioral abnormalities in zebrafish (Danio rerio), and the mechanisms involved. Chemosphere 2018, 191, 7-16. [CrossRef] [PubMed]

23. Vogl, C.; Grillitsch, B.; Wytek, R. Qualification of spontaneous undirected locomotor behavior of fish for sublethal toxicity testing. Part I. Variability of measurement parameters under general test conditions. Environ. Toxicol. Chem. 1999, 18, 2736-2742. [CrossRef]

24. Kane, A.S.; Salierno, J.D.; Gipson, G.T.; Molteno, T.C.A.; Hunter, C. A video-based movement analysis system to quantify behavioral stress responses of fish. Water Res. 2004, 38, 3993-4001. [CrossRef] [PubMed]

25. Fini, J.-B.; Mughal, B.B.; Le Mével, S.; Leemans, M.; Lettmann, M.; Spirhanzlova, P.; Affaticati, P.; Jenett, A.; Demeneix, B.A. Human amniotic fluid contaminants alter thyroid hormone signalling and early brain development in Xenopus embryos. Sci. Rep. 2017, 7, 43786. [CrossRef] [PubMed]

26. Denoël, M.; Libon, S.; Kestemont, P.; Brasseur, C.; Focant, J.-F.; De Pauw, E. Effects of a sublethal pesticide exposure on locomotor behavior: A video-tracking analysis in larval amphibians. Chemosphere 2013, 90, 945-951. [CrossRef] [PubMed]

27. Kuklina, I.; Kouba, A.; Kozák, P. Real-time monitoring of water quality using fish and crayfish as bio-indicators: A review. Environ. Monit. Assess. 2013, 185, 5043-5053. [CrossRef] [PubMed]

28. Huang, Y.; Campana, O.; Wlodkowic, D. A Millifluidic System for Analysis of Daphnia magna Locomotory Responses to Water-born Toxicants. Sci. Rep. 2017, 7, 17603. [CrossRef] [PubMed]

29. Tooming, E. The Sublethal Effects of Neurotoxic Insecticides on the Basic Behaviours of Agriculturally Important Carabid Beetles. Ph.D. Thesis, Eesti Maaülikool, Tartu, Estonia, 2017.

30. Faimali, M.; Garaventa, F.; Piazza, V.; Greco, G.; Corrà, C.; Magillo, F.; Pittore, M.; Giacco, E.; Gallus, L.; Falugi, C.; et al. Swimming speed alteration of larvae of Balanus Amphitrite as a behavioural end-point for laboratory toxicological bioassays. Mar. Biol. 2006, 149, 87-96. [CrossRef]

31. Fiedler, P.C. Offshore entrainment of anchovy spawning habitat, eggs, and larvae by a displaced eddy in 1985. Calif. Coop. Ocean. Fish. Investig. Rep. 1986, 27, 144-152.

32. Genner, M.J.; Halliday, N.C.; Simpson, S.D.; Southward, A.J.; Hawkins, S.J.; Sims, D.W. Temperature-driven phenological changes within a marine larval fish assemblage. J. Plankton Res. 2010, 32, 699-708. [CrossRef]

33. Somarakis, S.; Drakopoulos, P.; Filippou, V. Distribution and abundance of larval fish in the northern Aegean Sea-Eastern Mediterranean-In relation to early summer oceanographic conditions. J. Plankton Res. 2002, 24, 339-358. [CrossRef]

34. Weis, J.S.; Weis, P. Tolerance and Stress in a Polluted Environment. Bioscience 1989, 39, 89-95. [CrossRef] 
35. Van Leeuwen, C.J. Ecotoxicological aspects of dithiocarbamates. In Rijkswaterstaat Communications No. 44; Rijkswaterstaat: Utrecht, The Netherlands, 1986.

36. OECD. OECD Guidelines for the Testing of Chemicals/Section 2: Effects on Biotic Systems Test No. 210: Fish, Early-Life Stage Toxicity Test; OECD Publishing: Paris, France, 1992; ISBN 9789264070103.

37. OECD. OECD Guidelines for the Testing of Chemicals, Section 2 Test No. 236: Fish Embryo Acute Toxicity (FET) Test; OECD Publishing: Paris, France, 2013; ISBN 9789264203709.

38. Wheeler, J.R.; Panter, G.H.; Weltje, L.; Thorpe, K.L.; Organization for Economic Co-operation and Development; United States Environmental Protection Agency. Test concentration setting for fish in vivo endocrine screening assays. Chemosphere 2013, 92, 1067-1076. [CrossRef] [PubMed]

39. McKim, J.M. Evaluation of Tests with Early Life Stages of Fish for Predicting Long-Term Toxicity. J. Fish. Res. Board Can. 1977, 34, 1148-1154. [CrossRef]

40. Maya, N.; Crispo, C.; McFarland, V. Toxicity of extracts from municipal wastewater to early life stages of Japanese medaka (Oryzias latipes) to evaluate removals of micropollutants by wastewater treatment. Environ. Toxicol. Chem. 2017, 37, 136-144. [CrossRef] [PubMed]

41. Raine, J.C.; Turcotte, D.; Tumber, V.; Peru, K.M.; Wang, Z.; Yang, C.; Headley, J.V.; Parrott, J.L. The effect of oil sands tailings pond sediments on embryo-larval walleye (Sander vitreus). Environ. Pollut. 2017, 229, 798-809. [CrossRef] [PubMed]

42. Schreiber, B.; Fischer, J.; Schiwy, S.; Hollert, H.; Schulz, R. Towards more ecological relevance in sediment toxicity testing with fish: Evaluation of multiple bioassays with embryos of the benthic weatherfish (Misgurnus fossilis). Sci. Total Environ. 2017, 619-620, 391-400. [CrossRef] [PubMed]

43. Yu, Y.; Nie, F.; Hay, A.; Lin, H.; Ma, Y.; Ju, X.; Gong, D.; Chen, J.; Gooneratne, R. Histopathological changes in zebrafish embryos exposed to DLPCBs extract from Zhanjiang coastal sediment. Environ. Monit. Assess. 2017, 189, 289. [CrossRef] [PubMed]

44. Whitehead, P.J.P. Fishes of the North-Eastern Atlantic and the Mediterranean; UNESCO: Paris, France, 1986.

45. Healey, M.C. The distribution and abundance of sand gobies, Gobius minutus, in the Ythan estuary. J. Zool. 1971, 163, 177-228. [CrossRef]

46. Fonds, M.; Van Buurt, G. The influence of temperature and salinity on development and survival of goby eggs (Pisces, Gobiidae). Hydrobiol. Bull. 1974, 8, 110-116. [CrossRef]

47. Hesthagen, I.H. Migrations, breeding, and growth in Pomatoschistus minutus (Pallas) (Pisces, Gobiidae) in Oslofjorden, Norway. Sarsia 1977, 63, 17-26. [CrossRef]

48. Breder, C.M.; Rosen, D.E. Modes of Reproduction in Fishes; Natural History Press: Garden City, NY, USA, 1966.

49. Forsgren, E. Sexual selection and sex roles in the sand goby. Behav. Conserv. Littoral Fishes 1999, $249-274$.

50. Hesthagen, I.H. Gobies of the genus Pomatoschistus as nest-builders. Fauna 1979, 32, 52-56.

51. Lissåker, M.; Kvarnemo, C. Ventilation or nest defense-Parental care trade-offs in a fish with male care. Behav. Ecol. Sociobiol. 2006, 60, 864-873. [CrossRef]

52. Blom, E.L.; Mück, I.; Heubel, K.; Svensson, O. Acoustic and visual courtship traits in two sympatric marine Gobiidae species-Pomatoschistus microps and Pomatoschistus minutus. Environ. Biol. Fishes 2016, 99, 999-1007. [CrossRef]

53. Lindström, K.; Hellström, M. Male size and parental care in the sand goby, Pomatoschistus minutus. Ethol. Ecol. Evol. 1993, 5, 97-106. [CrossRef]

54. Jones, A.G.; Walker, D.; Lindström, K.; Kvarnemo, C.; Avise, J.C. Surprising similarity of sneaking rates and genetic mating patterns in two populations of sand goby experiencing disparate sexual selection regimes. Mol. Ecol. 2001, 10, 461-469. [CrossRef] [PubMed]

55. Jones, A.G.; Walker, D.; Kvarnemo, C.; Lindström, K.; Avise, J.C. How cuckoldry can decrease the opportunity for sexual selection: Data and theory from a genetic parentage analysis of the sand goby, Pomatoschistus minutus. Proc. Natl. Acad. Sci. USA 2001, 98, 9151-9156. [CrossRef] [PubMed]

56. Singer, A.; Kvarnemo, C.; Lindström, K.; Svensson, O. Genetic mating patterns studied in pools with manipulated nest site availability in two populations of Pomatoschistus minutus. J. Evol. Biol. 2006, 19, 1641-1650. [CrossRef] [PubMed]

57. Saaristo, M.; Craft, J.A.; Lehtonen, K.K.; Lindström, K. Sand goby (Pomatoschistus minutus) males exposed to an endocrine disrupting chemical fail in nest and mate competition. Horm. Behav. 2009, 56, 315-321. [CrossRef] [PubMed] 
58. Saaristo, M.; Craft, J.A.; Lehtonen, K.K.; Björk, H.; Lindström, K. Disruption of sexual selection in sand gobies (Pomatoschistus minutus) by $17 \alpha$-ethinyl estradiol, an endocrine disruptor. Horm. Behav. 2009, 55, 530-537. [CrossRef] [PubMed]

59. Robinson, C.D.; Brown, E.; Craft, J.A.; Davies, I.M.; Moffat, C.F.; Pirie, D.; Robertson, F.; Stagg, R.M.; Struthers, S. Effects of sewage effluent and ethynyl oestradiol upon molecular markers of oestrogenic exposure, maturation and reproductive success in the sand goby (Pomatoschistus minutus, Pallas). Aquat. Toxicol. 2003, 62, 119-134. [CrossRef]

60. Robinson, C.D.; Brown, E.; Craft, J.A.; Davies, I.M.; Megginson, C.; Miller, C.; Moffat, C.F. Bioindicators and reproductive effects of prolonged $17 \beta$-oestradiol exposure in a marine fish, the sand goby (Pomatoschistus minutus). Aquat. Toxicol. 2007, 81, 397-408. [CrossRef] [PubMed]

61. Waring, C.P.; Stagg, R.M.; Fretwell, K.; McLay, H.A.; Costello, M.J. The impact of sewage sludge exposure on the reproduction of the sand goby, Pomatoschistus minutus. Environ. Pollut. 1996, 93, 17-25. [CrossRef]

62. Saaristo, M.; Craft, J.A.; Lehtonen, K.K.; Lindström, K. An endocrine disrupting chemical changes courtship and parental care in the sand goby. Aquat. Toxicol. 2010, 97, 285-292. [CrossRef] [PubMed]

63. Matthiessen, P.; Allen, Y.; Bamber, S.; Craft, J.; Hurst, M.; Hutchinson, T.; Feist, S.; Katsiadaki, I.; Kirby, M.; Robinson, C.; et al. The impact of oestrogenic and androgenic contamination on marine organisms in the United Kingdom-Summary of the EDMAR programme. Mar. Environ. Res. 2002, 54, 645-649. [CrossRef]

64. Robinson, C.D.; Craft, J.A.; Moffat, C.F.; Davies, I.M.; Brown, E.S.; Megginson, C. Oestrogenic markers and reduced population fertile egg production in a sand goby partial life-cycle test. Mar. Environ. Res. 2004, 58, 147-150. [CrossRef] [PubMed]

65. Solé, M.; Kopecka, J.; Parra, L.M.G. de la Seasonal variations of selected biomarkers in sand gobies Pomatoschistus minutus from the Guadalquivir Estuary, Southwest Spain. Arch. Environ. Contam. Toxicol. 2006, 50, 249-255. [CrossRef] [PubMed]

66. Humble, J.L.; Saaristo, M.; Lindström, K. Effects of $17 \alpha$-ethinyl estradiol exposure on estrogen receptors $\alpha$ and $\beta$ and vitellogenins $A, B$ and $C$ mRNA expression in the liver of sand goby (Pomatoschistus minutus). Mar. Environ. Res. 2014, 96, 12-18. [CrossRef] [PubMed]

67. Kvarnemo, C. Temperature differentially affects male and female reproductive rates in the sand goby: Consequences for operational sex ratio. Proc. R. Soc. Lond. B 1994, 256, 151-156. [CrossRef]

68. Dell'Omo, G. Behavioural Ecotoxicology; John Wiley \& Sons: Hoboken, NJ, USA, 2002; ISBN 9780471968528.

69. Vignet, C.; Bégout, M.-L.; Péan, S.; Lyphout, L.; Leguay, D.; Cousin, X. Systematic screening of behavioral responses in two zebrafish strains. Zebrafish 2013, 10, 365-375. [CrossRef] [PubMed]

70. Rihel, J.; Schier, A.F. Behavioral screening for neuroactive drugs in zebrafish. Dev. Neurobiol. 2012, 72, 373-385. [CrossRef] [PubMed]

71. Staples, C.A.; Adams, W.J.; Parkerton, T.F.; Gorsuch, J.W.; Biddinger, G.R.; Reinert, K.H. Aquatic toxicity of eighteen phthalate esters. Environ. Toxicol. Chem. 1997, 16, 875-891. [CrossRef]

72. Grosell, M.; Blanchard, J.; Brix, K.V.; Gerdes, R. Physiology is pivotal for interactions between salinity and acute copper toxicity to fish and invertebrates. Aquat. Toxicol. 2007, 84, 162-172. [CrossRef] [PubMed]

73. Jantzen, C.E.; Annunziato, K.A.; Bugel, S.M.; Cooper, K.R. PFOS, PFNA, and PFOA sub-lethal exposure to embryonic zebrafish have different toxicity profiles in terms of morphometrics, behavior and gene expression. Aquat. Toxicol. 2016, 175, 160-170. [CrossRef] [PubMed]

74. Agus, H.H.; Sümer, S.; Erkoç, F. Toxicity and molecular effects of di-n-butyl phthalate (DBP) on CYP1A, SOD, and GPx in Cyprinus carpio (common carp). Environ. Monit. Assess. 2015, 187, 423. [CrossRef] [PubMed]

75. Chaparro-Ortega, A.; Betancourt, M.; Rosas, P.; Vázquez-Cuevas, F.G.; Chavira, R.; Bonilla, E.; Casas, E.; Ducolomb, Y. Endocrine disruptor effect of perfluorooctane sulfonic acid (PFOS) and perfluorooctanoic acid (PFOA) on porcine ovarian cell steroidogenesis. Toxicol. In Vitro 2018, 46, 86-93. [CrossRef] [PubMed]

76. Boas, M.; Frederiksen, H.; Feldt-Rasmussen, U.; Skakkebæk, N.E.; Hegedüs, L.; Hilsted, L.; Juul, A.; Main, K.M. Childhood exposure to phthalates: Associations with thyroid function, insulin-like growth factor I, and growth. Environ. Health Perspect. 2010, 118, 1458-1464. [CrossRef] [PubMed]

77. Martin, M.T.; Brennan, R.J.; Hu, W.; Ayanoglu, E.; Lau, C.; Ren, H.; Wood, C.R.; Corton, J.C.; Kavlock, R.J.; Dix, D.J. Toxicogenomic study of triazole fungicides and perfluoroalkyl acids in rat livers predicts toxicity and categorizes chemicals based on mechanisms of toxicity. Toxicol. Sci. 2007, 97, 595-613. [CrossRef] [PubMed] 
78. Mathieu-Denoncourt, J.; Wallace, S.J.; de Solla, S.R.; Langlois, V.S. Plasticizer endocrine disruption: Highlighting developmental and reproductive effects in mammals and non-mammalian aquatic species. Gen. Comp. Endocrinol. 2015, 219, 74-88. [CrossRef] [PubMed]

79. Vandenberg, L.N.; Colborn, T.; Hayes, T.B.; Heindel, J.J.; Jacobs, D.R., Jr.; Lee, D.-H.; Shioda, T.; Soto, A.M.; vom Saal, F.S.; Welshons, W.V.; et al. Hormones and endocrine-disrupting chemicals: Low-dose effects and nonmonotonic dose responses. Endocr. Rev. 2012, 33, 378-455. [CrossRef] [PubMed]

80. Scott, G.R.; Sloman, K.A. The effects of environmental pollutants on complex fish behaviour: Integrating behavioural and physiological indicators of toxicity. Aquat. Toxicol. 2004, 68, 369-392. [CrossRef] [PubMed]

81. Gerhardt, A. Aquatic behavioral ecotoxicology-Prospects and limitations. Hum. Ecol. Risk Assess. 2007, 13, 481-491. [CrossRef]

82. Gerhardt, A.; Janssens de Bisthoven, L.; Soares, A.M.V. Evidence for the Stepwise Stress Model: Gambusia holbrooki and Daphnia magna under acid mine drainage and acidified reference water stress. Environ. Sci. Technol. 2005, 39, 4150-4158. [CrossRef] [PubMed]

83. Gaetke, L.M.; Chow, C.K. Copper toxicity, oxidative stress, and antioxidant nutrients. Toxicology 2003, 189, 147-163. [CrossRef]

84. Aly, H.A.; Hassan, M.H.; El-Beshbishy, H.A.; Alahdal, A.M.; Osman, A.-M.M. Dibutyl phthalate induces oxidative stress and impairs spermatogenesis in adult rats. Toxicol. Ind. Health 2016, 32, 1467-1477. [CrossRef] [PubMed]

85. Ellis, L.D.; Seibert, J.; Soanes, K.H. Distinct models of induced hyperactivity in zebrafish larvae. Brain Res. 2012, 1449, 46-59. [CrossRef] [PubMed]

86. Saili, K.S.; Corvi, M.M.; Weber, D.N.; Patel, A.U.; Das, S.R.; Przybyla, J.; Anderson, K.A.; Tanguay, R.L. Neurodevelopmental low-dose bisphenol A exposure leads to early life-stage hyperactivity and learning deficits in adult zebrafish. Toxicology 2012, 291, 83-92. [CrossRef] [PubMed]

87. Huang, Y.; Cartlidge, R.; Walpitagama, M.; Kaslin, J.; Campana, O.; Wlodkowic, D. Unsuitable use of DMSO for assessing behavioral endpoints in aquatic model species. Sci. Total Environ. 2018, 615, 107-114. [CrossRef] [PubMed]

88. Kvarnemo, C. Food affects the potential reproductive rates of sand goby females but not of males. Behav. Ecol. 1997, 8, 605-611. [CrossRef]

89. Kullander, S.O.; Nyman, L.; Jilg, K.; Delling, B. Nationalnyckeln Till Sveriges Flora och Fauna; Strålfeniga Fiskar. Actinopterygii; ArtDatabanken SLU: Uppsala, Sweden, 2012.

90. Huyse, T.; Houdt, J.V.; Volckaert, F.A.M. Paleoclimatic history and vicariant speciation in the "sand goby" group (Gobiidae, Teleostei). Mol. Phylogenet. Evol. 2004, 32, 324-336. [CrossRef] [PubMed]

91. Svensson, O.; Gräns, J.; Celander, M.C.; Havenhand, J.; Leder, E.H.; Lindström, K.; Schöld, S.; van Oosterhout, C.; Kvarnemo, C. Immigrant reproductive dysfunction facilitates ecological speciation. Evolution 2017, 71, 2510-2521. [CrossRef] [PubMed]

92. Fonds, M. Remarks on the rearing of gobies (Pomatoschistus minutus and P. lozanoi) for experimental purposes. Helgol. Wiss. Meeresunters 1970, 20, 620-628. [CrossRef]

93. Unger, L.M. Nest defense by deceit in the fathead minnow, Pimephales promelas. Behav. Ecol. Sociobiol. 1983, 13, 125-130. [CrossRef]

94. Iwamatsu, T. Stages of normal development in the medaka Oryzias latipes. Mech. Dev. 2004, 121, 605-618. [CrossRef] [PubMed]

95. Ehrenberg, S.Z.; Ejdung, G. Daily activity pattern of the sand goby, Pomatoschistus minutus (Pisces), at low light intensity. Hydrobiologia 2008, 603, 129-137. [CrossRef]

96. Gustavsson, M.B.; Magnér, J.; Almroth, B.C.; Eriksson, M.K.; Sturve, J.; Backhaus, T. Chemical monitoring of Swedish coastal waters indicates common exceedances of environmental thresholds, both for individual substances as well as their mixtures. Mar. Pollut. Bull. 2017, 122, 409-419. [CrossRef] [PubMed] 
97. OECD. OECD Guidelines for the Testing of Chemicals/OECD Series on Testing and Assessment Guidance Document on Aquatic Toxicity Testing of Difficult Substances and Mixtures; OECD Publishing: Paris, France, 2002; ISBN 9789264078406.

98. R Core Team (2013). R: A language and environment for statistical computing. R Foundation for Statistical Computing: Vienna, Austria. Available online: http:/ / www.R-project.org/ (accessed on 15 July 2017). 